\title{
THE EFFECT OF PROGRAMME CONTEXT ON MEMORY FOR HUMOROUS TELEVISION ADVERTISEMENTS IN JAPAN
}

\author{
Adrian FURNHAM ${ }^{1)}$ and Tadataka MORI ${ }^{1)}$ \\ 1) University College London, U.K.
}

\begin{abstract}
This study examined the effect of programme context on the memory for humorous television advertisements among a young male Japanese sample $(N=136)$ aged 16 to 17 years. Participants were given free and cued recall tests. The relationship between the involvement and enjoyment properties of the programme and memory for the advertisements was investigated for a set of six humorous and non-humorous advertisements embedded within two programme contexts - a mid-day news and a light entertainment show. The two sets of advertisements were for matching products, and were selected from a sample of 40 advertisements. Findings indicate that free recall for advertisements was affected by programme type with memory for advertisements was better from light entertainment show than from the news. Additionally, memory for humorous advertisements was better than that for nonhumorous advertisements. There were no significant interactions showing no advantage for memory for humorous advertisements in non-humorous programmes and vice-versa.
\end{abstract}

Key words: television advertisements, memory, context effects

\section{Television programmes and advertisements}

With the increase of multi-channel television markets, competition for television audiences has become more acute. More available channels inevitably leads to audience fragmentation, which forces advertisers and media planners to know more about the demographics and psychographics of the audience (Gunter \& Furnham, 1992). However, another very important factor is the degree to which viewers are involved with, and attentive to, what they are watching (Gunter \& Wober, 1992).

Many aspects of television programmes are believed to influence advertising effectiveness as measured by various factors like brand memory. They are such as programme-induced viewer mood (Axelrod, 1963; Goldberg \& Gorn, 1987; Kamins, Marks, \& Skinner, 1991; Schumann, 1986), programme-advertisement congruity (Bello, Pitts, \& Etzel, 1983; Hansen, Barry, Reed, \& McGill, 1976; Horn \& McEwan, 1982; Johnson, 1981; Kamins, Marks, \& Skinner, 1991; Lambert, 1980; Murphy, Cunningham, \& Wilcox, 1979), programme-induced viewer excitement (Singh, Churchill, \& Hitchon, 1987), attitude or liking for the programme (Clancy \& Kweskin, 1971; Leach, 1981; Schumann, 1986; Thorson \& Reeves, 1986), programme-induced viewer drive for closure (Kennedy, 1971) and programme impact appeal (Television Audience Assessment, 1984). In addition, programme-induced viewer involvement has been reported to be

Reprint requests should be directed to Adrian Furnham, Department of Psychology, University College London, 26 Bedford Way, London WC1H 0AP, UK (E-mail: a.furnham@ucl.ac.uk). 
important factor in advertising effectiveness (Bryant \& Comisky, 1978; Park \& McLung, 1986; Siebert, 1978; Soldow \& Principe, 1981; Thorson \& Reeves, 1986; Thorson, Reeves \& Schleuder, 1985). However, these studies have revealed very mixed results and it is not clear which of the above effects is robust systematically effecting advertisement memory over different conditions.

\section{Programme-induced viewer involvement}

As well as other aspects of television programmes, studies into the effect of programme-induced viewer involvement revealed mixed results (Bryant \& Comisky, 1978; Lloyd \& Clancy, 1991; Park \& McLung, 1986; Siebert, 1978; Thorson \& Reeves, 1986; Thorson, Reeves, \& Schleuder, 1985). Some researchers reported positive relationship between viewer's involvement and their recall of adverts (Johnson, 1992; Lloyd \& Clancy, 1991), whereas others found a negative relationship (Furnham, Gunter, \& Walsh, 1998; Furnham, Bergland, \& Gunter, 2002; Gunter, Furnham, \& Beeson, 1997; Norris \& Colman, 1992).

Schwerin (1958), suggested that the effectiveness of an advertisement could in part be determined by programme content and found a negative relationship between viewer's involvement in a programme and recall of advertisements placed within it. He explained this finding by suggesting that viewers experience an unwelcomed interruption when they are involved in the programme, which leads them to poor recall of the advertisements embedded with it. Axelrod (1963) basically supported Schwerin's hypothesis, but he suggested that the effect varies by product whereas Schwerin explained the effect in terms of the difference of time effects.

Burke Marketing Research (1978) reported little variation in recall of advertisements as a function of programme type in a study using dramas, movies, situation comedies, and other programmes. Research elsewhere, however, has indicated that there is a positive effect of programme context on advertisement recall (Barclay, Doub, \& McMurtney, 1965). Furthermore, Norris and Colman (1993) suggested that advertisement recall varies across viewers of the same programme as a function of their degree of involvement with the programme.

Howard (1977) suggested that people with low involvement in a programme tend not to have their attention disrupted and simply respond to the advertisement, which results in a good recall. Kennedy (1971) supported this view and explained it in terms of viewer's desires for the closure of the programme. In other words, viewers have a desire for the final resolution and any interruption that might occur during programmes would result in frustration. In his experiment, he tested this hypothesis comparing suspense-thrillers and comedy. He found that people watching thrillers were more involved in the programme and so produced a stronger desire for closure than those who watched comedy.

Soldow and Principe (1981) compared brand name and sales message recall from advertisements carried either in an involving or relatively non-involving programme. They found that recall of both measures was worse from the former and that attitudes toward the advertisements showed that more annoyance was caused by advertisements to viewers of the involving programme than to viewers of the non-involving programmes. 
Norris and Colman (1993) suggested that these inconsistencies could be explained by the operation of selective exposure in studies reporting positive relationship. The lack of agreement about the operational definitions of the predictor variables measured is also mentioned as another possible factor.

Certainly there remains no consensus as to the effect of viewer involvement on memory for advertisements or the mechanism to explain how it works.

\section{Humorous advertisements and mood}

As additional support to the hypothesis that programme content effects advertisement effectiveness, a few studies have examined humour within advertisements to find out the effect on the viewers' mood and brand recall. There are however limitations using humour not only in advertising research; for instance, it is very personal and to some extent, culturally determined phenomenon. However, recent researchers examining humour in advertising tend to focus on mood congruity on memory for humorous compared to non-humorous advertisements.

Murphy, Cunningham, and Wilcox (1979) tested the performance of humorous and non-humorous advertisements by measuring free and cued recall of the same advertisements in three different environments (situation comedy, action/adventure and documentary). They found, with the free recall test, that humorous advertisements were found to be better recalled within a documentary, whereas non-humorous advertisements were found to be better remembered with the situation comedy. Although the results were non-significant, what this finding suggested is that television programme could interact with advertisement content to effect recall, especially when viewers experienced moodcontrast. This finding was further investigated by Furnham, Gunter, and Walsh (1998) in a investigation of the effect of programme content. In their experiment, advertisements were found to be better recalled when shown within a non-humorous programme. Further they found that humorous advertisements were better freely recalled than non-humorous advertisements when placed in non-humorous programme content. Non-humorous advertisement also fared better when shown with non-humorous than with humorous programme content, however not to the same extent as did humorous advertisements. That is, serious programme content may provide a generally more favourable environment for advertising in so far as immediate recall of commercial messages is concerned. This finding could be explained in terms of programme-induced mood.

Goldberg and Gorn (1987) investigated the effect of programme-induced mood on recall of adverts. They hypothesized that the mood induced by the programme would continue to be experienced during the commercial break, leading the viewers to evaluate the adverts as more effective when viewed in the context of a happy programme than when viewed in the context of a sad one. Results supported this view: advertisements seen within a happy programme being rated as more effective than when seen within a sad programme. The type of advertisement also makes a difference with emotional advertisements leading to generally more positive reactions than informational advertisements. Those who saw emotional advertisements were reported as feeling happier than those who saw informational ones. A significant programme by 
advertisements interaction was also obtained for viewer's mood during the advertisement, with the programme effect being greater for those viewing emotional advertisements than viewing informational ones.

Kamins, Marks, and Skinner (1991) also examined the effect of induced mood by programme using happy and sad television programmes. They investigated the effect on subjects' reactions to embedded happy and sad advertisements. They found a consistency effect, whereby "happy advertisements" were better to be preferred when shown within a "happy programme", and "sad advertisements" were better to be liked within "sad programmes".

Hoffman and Batra (1991) argued that there are several dimensions of involvement which should be considered in any analysis of effects on advertising recall. Basically they distinguished three types of programme effects: (1) high cognitive impact (e.g. news), (2) high affective impact (e.g. peak-time soap operas) and (3) low impact (e.g. situation comedy). In their findings, viewers with high cognitive impact paid all, or most, of their attention to the programme and were not distracted when the programme was on, whereas those who with low impact paid little attention to the programme and would often talk during the programme. These viewer's reactions result in the good recall of advertisement messages with high cognitive impact and bad performance with low impact. However, it should be noted that the category "low impact" merely refers to contexts that are neither cognitively nor affectively involving. Moreover Norris and Colman (1993) pointed out that Hoffman and Batra's cognitive involvement corresponds to what other researchers have called simply the factor of 'involvement', while their affective involvement category plausibly correspond to an 'entertainment' and 'enjoyment' factor which found in other studies.

In addition, Norris and Colman (1993) questioned the definition of the predictor variable involvement. In other words, it is not clear that all rating scales used measured the same underlying variable of induced programme involvement. This in turn leads to the inconsistent results. Therefore, they carried out a study with methodological improvements by choosing viewer's involvement as a predictor variable, and found that viewer's recall and recognition of advertisement correlated negatively with their rating of the programme as involving.

Norris and Colman (1994) went on to generate empirical definitions of involvement, entertainment and enjoyment from a cluster analysis, and revealed that involvement is quite distinct from entertainment and enjoyment. This finding suggests that entertainment and enjoyment should not be considered interchangeable with involvement (Furnham, Gunter, \& Walsh, 1998).

Norris and Colman (1994) showed that, although the rating of the programme as entertaining, enjoyable, humorous, funny, exciting and amusing were correlated negatively, but non-significantly, with their memory scores. This finding was later supported by the study of Furnham, Gunter, and Walsh (1998). Although they found the negative relation between the audience's evaluation and memory for advertisements, the relation was not significant with memory for advertising. Additionally, they found the significance of the programme by advert type interaction did depend on the type of 
measure being used. It was significant for free recall but not for cued recall. They suggested that this may be because of the different amount of promotional information humorous and non-humorous adverts contain. Another relevant factor was the prior familiarity with the adverts which rendered the cued recall and recognition tasks relatively easy.

This study is an adaptation and cross-cultural replication of Furnham, Gunter, and Walsh (1998) experiment looking at programme advertisement congruity on memory for humorous advertisements. It examines the relationship between viewer's rating scales of a programme and their recall of advertisement embedded within. The current experiment essentially replicated this study using Japanese advertisements and with a Japanese audience. Humour is know to vary significantly across culture: both visual and verbal humour, as well as the way and place it can be expressed (Trompenaars, 1993). This study is therefore a cross-cultural replication testing the same hypotheses with different advertisements embedded in different programmes and with a different audience.

The hypotheses tested in this study are:

(H1) Audience evaluation of programme does not affect their memory (free and recall) of the advertisement embedded within it.

(H2) The humorous advertisements are freely recalled better than non-humorous advertisements when placed in non-humorous programme content (mood-contrast).

\section{METHOD}

Participants:

The participants were 136 male adolescents from Tezukayama-Izumigaoka high school in Japan, aged between 15 to 16 years ( mean $=15.85 \mathrm{yrs}, S D=0.36$ ), and randomly allocated to four treatment conditions:

Group One $(N=34)$ - Humorous programme with humorous advertisements;

Group Two $(N=34)$ - Non-humorous programme with Non-humorous advertisements;

Group Three $(N=34)$ - Humorous programme with Non-humorous advertisements;

Group Four $(N=34)$ - Non-humorous programme with humorous advertisements.

There was no significant difference in their ages of participants in four conditions. They reported that they watch television 2.37 hours per day $(S D=1.29)$. Again this was not different across the four groups.

\section{Materials:}

Programmes: The programmes comprised an episode from light entertainment show 'GAKKOU HE IKOU' (Let's go to school) (length: 24 minutes and 52 seconds excluding the centre advertising break) and a mid-day news 'NEWS SCRAMBLE' (length 19 minutes and 25 seconds excluding the centre advertising break).

Advertisements: Six advertisements were edited into the centre break of each programme. There were two sequences of advertisements, humorous adverts (total length: 3 minutes and 2 seconds) and nonhumorous advertisements (total length: 2 minutes and 18 seconds). The advertising breaks occurred 16 minutes and 13 seconds from the end of the news programme and 12 minutes and 11 seconds from the end of light entertainment show. The 12 adverts were selected from a sample advertisement by five people chosen for their knowledge of, and interest in, Japanese television advertisements. The six advertisements scored as most humorous and the six scored as least humorous were chosen for final use. The humorous advertisements comprised message for: PIREPARESU (mothball), POCARISWEAT (drinks), MY LINE TELECOM (new service from a telephone company), APAMAN SHOP (residential information 
magazine), PAFURE SWEET (calorie-less sugar) and SUKIYANEN (instant noodle). The non-humorous advertisements comprised: PEDIGREE CHUM (dog-food), LUX SUPERRICH (shampoo), DEMIO ALLETA (car), SERTIO (napkin for the old), ROUKIN (loan company) and DAVE (facial cleansing cream).

Questionnaires: Questionnaires were used to measure the participants' perceptions of the programme and the television commercials. After filling in details of their age, sex and parental occupation and television watching habits (per day), they then were asked if they had ever seen the programme before the experiment. Nearly all had not seen that particular programme before. Some did admit to have having seen the particular advertisements before (around $10 \%$ in total) but there was no significant difference between the four groups. Ideally both programme and advertisements should have been new to the participant.

(1) Programme ratings: Participants respond to a set of 17 seven-point, bipolar adjectival scales (entertaining, enjoyable, exciting, happy, cheerful, humorous, funny, amusing, fun, stimulating, interesting, absorbing, thought-provoking, involved relaxing, clever and informative). The first 14 of these were taken from the empirical definition of enjoyment, entertainment and involvement as derived from a full-scale cluster analysis (Norris \& Colman, 1994), and the rest of them were adopted from Furnham, Gunter, and Walsh (1998).

(2) Free recall: Participants were asked to write down as much as they could remember about all the television advertisements they had been shown.

(3) Product recognition: Participants were asked to identify the products from 48 randomly chosen products that were commonly advertised on television.

(4) Brand name recognition: Each brand name was randomly placed under the relevant products type with five other possible brand names. Participants were then asked to identify which brand name had been shown in the advertisement.

(5) Cued recall: Participants were given the name of the brand which shown in the advertisement and asked two questions in a multiple-choice format, about the content of the advertisement message.

Free recall description of the advertisements were marked out of 32 according to a list of salient points complied in advance. In the scoring of the recognition measures one point was awarded for a correct choice and zero for incorrect one. Cued recall was scored with one for a correct multiple-choice answer and zero for incorrect one scored test. In the same way as reliability check of programme dividing, five students checked the scoring for reliability. The mean correlation between observers was $r=92$. The free and cued recall scores were combined to form global recall scores. Also the two sets of recognition measures were likewise combined to produce a global recognition score.

\section{Procedure:}

All participants were randomly assigned to one of four treatment conditions. All participants in each condition were tested together. In total, there were four experimental groups which were run in a-day period. They had been told that they were taking part in a television programme-evaluation experiment without making mention of the advertisements. After filling in the questionnaires, they were shown a television programme. After watching the programme and advertisements, the participants asked to complete the questionnaires, beginning with general informational form followed by the programme rating instrument and then recall and recognition tests. Each of those questionnaires had been given out separately and collected before subsequent questionnaire was distributed. By doing this, it was possible to minimize the opportunity to change earlier response in the light information provided in subsequent questionnaires. Participants were given three minutes to complete their personal details and the programme ratings, responding every scale. A further six minutes were given for the free recall test, and with two minutes each being allowed for the remaining memory test. These time duration settings were based on the experiment carried out by Furnham, Gunter, and Walsh (1998). 
Table 1. Programme Evaluation Factors

\begin{tabular}{lccc}
\hline & \multicolumn{3}{c}{ Loadings of the 17 ratings on the three factors } \\
\cline { 2 - 4 } & Humorous & Involving & Thought-provoking \\
\hline Funny & .93 & .02 & .01 \\
Amusing & .92 & .11 & .03 \\
Enjoyable & .91 & .34 & .02 \\
Entertaining & .90 & .23 & .01 \\
Humorous & .89 & .19 & .01 \\
Fun & .86 & .20 & .03 \\
Cheerful & .76 & .31 & .01 \\
Exciting & .72 & .33 & .15 \\
Informative & -.70 & .49 & .01 \\
Happy & .60 & .46 & .02 \\
Relaxing & .54 & .20 & .01 \\
Clever & .54 & .39 & -.37 \\
Stimulating & .01 & .91 & .01 \\
Interesting & .28 & .82 & .01 \\
Absorbing & .56 & .63 & .03 \\
Involving & .48 & .53 & .01 \\
Thought-provoking & .02 & .16 & .86 \\
\hline Eigenvalue & 9.34 & 2.08 & 1.04 \\
\hline Variance & $45.95 \%$ & $12.25 \%$ & 6.12 \\
\hline
\end{tabular}

\section{RESULTS}

\section{Programme ratings factors}

The programme evaluation data were subjected to factor analysis with VARIMAX rotation in order to examine the dimensional structure of participants' programme ratings. This analysis was computed on aggregated reaction data across the sample as a whole. Three significant factors (humorous, involving and thought-provoking) emerged by using a Scree Test, accounting for $\%$ of the variance. These data are summarised in Table 1.

The factors were labelled Humorous defined by twelve items, Involving defined by four items and Thought-provoking defined by one item. All evaluative items were accounted for across these three factors. 
Table 2. Mean Programme Evaluation Scores with (Standard Deviations)

\begin{tabular}{lclc}
\hline \multicolumn{1}{c}{ GROUP } & Humorous & \multicolumn{1}{c}{ Involving } & Thought-provoking \\
\hline Humorous & $3.69(1.06)$ & $3.61(1.40)$ & $2.87(1.91)$ \\
Non-humorous & $1.78(0.91)$ & $2.89(1.38)$ & $2.91(1.69)$ \\
mean & $2.74(1.36)$ & $3.25(1.44)$ & $2.89(1.80)$ \\
$F(1,135)$ & $135.97 * *$ & $9.01^{*}$ & .02 \\
\hline
\end{tabular}

$* p<.05, * * p<.01$

Table 3. Partial Correlation between Programme Evaluation and Memory for Advertisements

\begin{tabular}{lccc}
\hline & Humorous & Involving & Thought-provoking \\
\hline Free Recall & $.14^{*}$ & $.15^{*}$ & .06 \\
Cued Recall & .13 & .03 & .15 \\
Product Recognition & -.00 & .05 & .01 \\
Brand Recognition & -.06 & -.04 & .04 \\
Global Recall & $.17^{*}$ & .12 & .13 \\
Global Recognition & -.01 & -.00 & .04 \\
Global Memory & .10 & .09 & .11 \\
\hline
\end{tabular}

$* p<.05(N=136)$

\section{Programme ratings differences}

By aggregating over the rating scale data on each factor, single-factor scores were produced for Enjoyable, Involving and Thought-provoking. A series of one-way ANOVAs were computed to determine if the two programmes differed in terms of these subjective audience evaluation scales. The results are summarized in Table 2, indicating that two programmes were found to differ significantly in terms of their perceived enjoyment, and involvement. Participants perceived the light entertainment television programme as more enjoyable and involving than the news programme.

\section{Programme ratings and memory for advertisements}

To explore any relationship between subjective programme ratings and advertisement recall and recognition, second-order partial correlations (controlling for participants' age and number of hours of television watched per day) were computed between these measurements and the three programme evaluation dimensions. The results are shown in Table 3, showing that two of the correlations between participants' programme ratings and memory scores achieved statistical significance.

Overall the correlations were low. Three were significant. There was a significant positive correlation occurred between humorous rating and the involving rating and free 
Table 4. Mean Recall and Recognition Scores in Humorous and Non-humorous Advertisements

\begin{tabular}{lcccc}
\hline Type of Programme & \multicolumn{2}{c}{ Humorous Programme } & \multicolumn{2}{c}{ Non-Humorous Programme } \\
\hline $\begin{array}{c}\text { Type of } \\
\text { Advertisements }\end{array}$ & $\begin{array}{c}\text { Humorous } \\
\text { Advertisement } \\
\text { (Group1) }\end{array}$ & $\begin{array}{c}\text { Non-Humorous } \\
\text { Advertisement } \\
\text { (Group3) }\end{array}$ & $\begin{array}{c}\text { Humorous } \\
\text { Advertisement } \\
\text { (Group4) }\end{array}$ & $\begin{array}{c}\text { Non-Humorous } \\
\text { Advertisement } \\
\text { (Group2) }\end{array}$ \\
\hline$N$ & 34 & 34 & 34 & 34 \\
\hline Free Recall & 5.12 & 4.79 & 3.91 & 4.44 \\
Cued Recall & 10.24 & 8.76 & 9.53 & 7.82 \\
Product Recognition & 4.26 & 3.79 & 4.26 & 4.02 \\
Brand Recognition & 4.15 & 4.00 & 4.32 & 3.82 \\
Global Recall & 7.68 & 6.78 & 6.72 & 6.13 \\
Global Recognition & 4.21 & 3.90 & 4.29 & 3.93 \\
Global Memory & 5.94 & 5.34 & 5.51 & 5.03 \\
\hline
\end{tabular}

recall. There was also a positive correlation between the humurous rating and global recall. None of the correlations between the involvement rating or the through-provoking rating and memory scores achieved statistical significance.

To explore any relationship between single subjective programme rating and memory for advertisement, additional partial correlations (again the number of hours and participants' age were controlled) were computed between these measures and each single subjective evaluation. Various statistical significant figures were found between subjects' evaluation and memory scores. First, programme ratings of "informative" were negatively correlated with Cued Recall $(r=-.20, p<.05)$ and Global Recall $(r=-.20$, $p<.05)$. Secondly, significant positive correlations occurred between Free Recall and enjoyment $(r=.18, p<.05)$, excitement $(r=.17, p<.05)$. These two factors were cluster into humorous factor. Also various ratings were correlated positively with Global Recall: enjoyment $(r=0.20, p<.05)$, excitement $(r=.21, p<.05)$, humorous $(r=.17, p<.05)$, funny $(r=.18, p<.05)$ and amusing $(r=.17, p<.05)$. Again these five of twelve factors were defined as Humorous factor.

These results do suggest that rating of programme "enjoyment" levels were positively correlate with Free Recall and Global Recognition, which suggests that greater programme humorous was associated with greater recall of advertisement, and product and brand recognition. However, the size of the correlations certainly suggests the relationship is weak.

\section{Programme environment and memory for advertisements}

One-way ANCOVAs (controlling for prior familiarity with the programme series and number of hours of television watching per day) were computed to compare Free Recall and Cued Recall of advertisements and Brand and Product Recognition as a 
function of both type of programme and type of advertisement. The means are shown in Table 4.

A significant advertisement effect emerged for Cued Recall $(F(1,136)=23.18$, $p<.001)$, Global Recall $(F(1,136=4.70, p<.05)$ and Global Memory $(F(1,136)=5.71$, $p<.05)$. In each case memory for humorous advertisements was better than non-humorous ones.

A significant programme effect found with Cued Recall $(F(1,136)=6.39, p<.05)$, and Global Recall $(F(1,136)=7.05, p<.01)$. Cued Recall and Global Recall for memory of advertisement content was higher when they embedded in humorous rather than for nonhumorous programme.

There was no significant programme type by advertisement type interactions on any of the memory scores. This means the second hypothesis was not confirmed.

\section{DISCUSSION}

\section{Rating of programme}

Despite the fact that the subjective evaluations of programmes were different, the nature of programme content was also examined to determine its effect on memory for embedded advertisements. Advertisements used in the current experiment were found to be better recalled (in Cued Recall and Global Recall) when viewed within a humorous programme (light entertainment show) than within a non-humorous programme (mid-day news). This finding was inconsistent with the Hoffman and Batra (1991) study. In their study, the audience of low impact programmes (e.g. situation comedy, action-adventure) were thought to pay little attention to the programme, would talk often during the programme and leave the room at any point, which resulted in poor performance on memory test for advertising. These results concur with the suggestion of Norris and Colman (1993) in that the so-called 'low impact' category merely refers to contexts that are neither cognitively nor affectively involving. Moreover, 'entertainment' and 'enjoyment' factors were found to be more important.

Ratings of audience involvement with a programme were negatively related with advertisement recognition, signifying that the more involved audience were in a programme, the poorer was their recognition for advertising shown in that programme, while the rating of involvement were positively related to recall for advertisements. The involvement variable, however, was not significantly linked to advertising memory. Thus, as suggested by Furnham, Gunter, and Walsh (1998), this result suggests that involvement was not important factor to advertising recall and recognition.

Programme humorous ratings were positively correlated with memory for advertisements. Advertising recall apparently benefits from greater audience perception of humour from a programme.

\section{Rating of advertisements}

The overall patterns of the results suggest that memory for advertisements were 
better for humorous advertisements than non-humorous advertisements. Advertisements were found to be better remembered in Cued Recall and Global Recall. Inevitably, audience attention to an advertisement is effected by the presence of humour. Humour has been found to lead to increase attention, thereby increasing the effectiveness of information processing from the commercial message. Children particularly enjoy humour in advertising (Gunter \& Furnham, 1998). Perception of an advertisement as humorous was clearly related to the attraction that it had for the students.

However, statistical significance was found only for cued recall but not with free recall. As earlier findings by other researchers (Murphy, Cunningham \& Wilcox, 1979; Furnham, Gunter, \& Walsh, 1998) suggested prior subjective familiarity with the advertisements rendered the cued recall and recognition tasks comparatively easy, and ceiling effects may have therefore been operating although not to any great effect.

\section{Programme environment and memory}

Overall, the results show that humorous advertisements were recalled better than non-humorous advertisements. This finding partly confirms earlier findings (Murphy, Cunningham, \& Wilcox, 1979; Furnham, Gunter, \& Walsh, 1998). However, nonhumorous advertisements did not fare better when shown with non-humorous than with humorous programme content. In fact none of the seven interaction effects even approached significance. In contrast Furnham, Gunter, and Walsh (1998) suggested that serious programme content may provide a generally more favourable environment for advertisement in so far as immediate recall of commercial messages is concerned. Rather the results of current research suggest that humorous programme content generally provide comfortable surrounding to recognize memory for advertising.

The overall results are more likely to be consistent with the findings carried out by Goldberg and Gorn (1987) who investigated programme-induced mood upon recall of advertisements. Their findings indicated that the mood induced by the programme continue to be experienced during the commercial break, leading the viewer to evaluate the advertisement as more effective when viewed in the context of a happy programme than when viewed in the context of a sad one. In this current study, the mid-day news programme contained some information about the disaster in New York in September 2001.

Previous researchers have noted differences between males and females in their processing of advertisements. The difference in reactions of viewers to a range of content, including humour, sexual material, has implications for their possible reactions to the surrounding programme contexts that contain such material (Derks, 1992; Haig, 1988; Whipple \& Courtney, 1981). Certain products are aimed at specific gender. For instance, car advertisements have traditionally targeted males, and advertisements for domestic cleaning products have traditionally been aimed at females, although these trends have changed in recent years (Bellizzi \& Milner, 1991). Furnham, Bergland, and Gunter (2002) examined reactions of male and female respondents to advertisements in relation to surrounding programme context. They found that males have better recall of products that are traditionally regarded as male oriented (cars), while females performed better on 
remembering advertisements for products that are traditionally aimed at females (food products). Only male participants were examined in the current research. The advertisements used in this experiment included some female aimed materials, such as calorie-less sugar, food products, as well as that of male aimed materials (car advertisement). Future researchers may need to consider how interested their experimental audience is in the actual products advertised.

In essence, this study failed to replicate the interactive effects shown by Furnham, Gunter, and Walsh (1998) namely that free and cued recall of humorous advertisements are better in a non-humorous, compared to humorous programme setting.

There are two possible explanations for why these results were different from other studies particularly Furnham, Gunter, and Walsh (1998). First of all, the lightentertainment programme which was used in the current study was hosted by many famous characters. This may have contributed to the difference in participants' attention level to the programmes themselves. Secondly, the difference of the length of the advertisements used in the current study might affect participants' conditions. Comparatively, Japanese TV advertisements used in this experiment were shorter than that of advertisements in British study. The advertisement of the original experiment which carried out by Furnham, Gunter, and Walsh (1998) were comparatively longer (humorous advertisements: 4 minutes and 10 seconds, non-humorous advertisements: 3 minutes and 50 seconds) than those used in this experiment (humorous advertisements: minutes and seconds, non-humorous advertisements: 2 minutes and 18 seconds). These gaps are equal to the differences of the participants in the length of exposure to advertisements, which potentially cause difference in the degree of effect. In future studies, it may be necessary to control the length of both programmes and the advertisements to investigate the mood-congruence effect. Certainly the results of this study suggests that the congruence effect is far from robust and effected by many other factors.

Overall the results suggest advertisers and planners should use humorous advertisements in humorous programmes for better recall in viewers.

\section{REFERENCES}

Axelrod, J. N. 1963. Induced moods and attitudes towards products. Journal of Advertising Research, 3, 1924.

Barclay, W., Doub, R., \& McMurtney, L. 1965. Recall of TV commercials by time and programme slot. Journal of Advertising Research, 5, 41-47.

Bellizzi, J. A., \& Milner, L. 1991. Gender positioning of a traditionally male-dominated product. Journal of Advertising Research, 31, 72-79.

Bello, D. C., Pitts, R. E. \& Etzel, M. J. 1983. The communication effect of controversial sexual content in television programme and commercials. Journal of Advertising, 12, 32-42.

Bryant, J., \& Comisky, P. W. 1978. The effect of positioning a message within differentially cognitively involving portions of a television segment on recall of the message. Human Communication Research, 5, 63-75.

Burke Marketing Research. 1978. Day after recall of television norms. White Plans, NY: Author.

Clancy, K. J., \& Kweskin, D. M. 1971. TV commercial recall correlates. Journal of Advertising Research, 2, 
$18-20$.

Derks, P. 1992. Category and ratio scaling of sexual and innocent cartoons. Humour, 5, 319-330.

Furnham, A., Bergland, J., \& Gunter, B. 2002. Memory of television advertisements as a function of advertisement-progamme congruity. Applied Cognitive Psychology, 16, 525-545.

Furnham, A., Gunter, B., \& Walsh, D. 1998. Effects of programme context on memory for humorous television commercials. Applied Cognitive Psychology, 12, 555-567.

Goldberg, M. E., \& Gorn, G. J. 1987. Happy and sad TV programmes: How they affect reactions to commercials. Journal of Consumer Research, 14, 387-403.

Gunter, B., \& Furnham, A. 1992. Consumer profiles: An instroduction to psychographics. London: Routledge.

Gunter, B., \& Furnham, A. 1998. Children as consumers. London: Routledge.

Gunter, B., \& Wober, M. 1992. The reactive viewer. London: John Libbey.

Gunter, B., Furnham, A., \& Beeson, C. 1997. Recall of television advertisements as a function of programme evaluation. Journal of Psychology, 131, 541-554.

Haig, R. A. 1988. The anatomy of humour: Biopsychological and therapeutic perspectives. Springfield, IL: Charles C. Thomas.

Hansen, R. W., Barry T. E., Reed, H. H., \& McGill, M. E. 1976. Marketing applications of transactional analysis: Some empirical support for advertising. Journal of Advertising, 5, 16-21.

Hoffman, D. L., \& Batra, R. 1991. Viewer response to programmes: Dimensionality and performance. Journal of Advertising, 11, 23-27.

Horn, M. I., \& McEwan, W. J. 1982. The effect of programme content on commercial performance. Journal of Advertising, 11, 23-27.

Howard, J. 1977. Consumer Behaviour. New York: McGraw-Hill.

Johnson, R. 1981. An application of Helson's adaptation level theory to the problem of context in television advertising. Dissertation Abstracts International, 42, 439a.

Johnson, R. 1992, January 19. Attention seekers. Media Week, pp.14-18.

Kamins, M. A., Marks, L. J., \& Skinner, D. 1991. Television commercial evaluation in the content of programme-induced mood: Congruity versus consistency effects. Journal of Advertising, 20, 1-14.

Kennedy, J. R. 1971. How programme environment affects TV commercials. Journal of Advertising Research, 11, 33-38.

Lambert, D. R. 1980. Transactional analysis as a congruity paradigm for advertising recall. Journal of Advertising, 9, 37-41.

Leach, D. 1981, July 13. Should ads be tested? Advertising Age, pp.47-48.

Lloyd, D., \& Clancy, K. 1991. CPMs versus CPMIs: Implications for media planning. Journal of Advertising Research, 31, 34-44.

Murphy, J. H., Cunningham, I. C. M., \& Wilcox, G. B. 1979. The impact of programme environment on recall of humorous television commercials. Journal of Advertising, 8, 17-21.

Norris, C. E, \& Colman, A. M. 1993. Context effects on memory for television advertisements. Social Behaviour and Personality, 21, 279-296.

Norris, C. E., \& Colman, A. M. 1994. Effects of entertainment and enjoyment of television programmes on perception and memory of advertisements. Social Behaviour and Personality, 22, 365-376.

Park, C., \& McLung, G. 1986. The effects of TV programme involvement on involvement with commercials. Advances in Consumer Research, 13, 544-548.

Schumann, D. 1986. Programme impact on attitude toward TV commercials. In J. Seagert (Ed), Proceedings of the Division of Consumer Psychology (pp. 67-73). Washington, DC: APA.

Schwerin, H. S. 1958. Do today's programme provide the wrong commercial climate? Television Magazine, 15, 44-47, 90-91.

Siebert, D. 1978. The effect of programme context on commercial recall. Paper presented at a meeting of the Association of National Advisers television workshop. New york: March.

Singh, S., Churchill, G., \& Hitchon, J. 1987. The intensifying effects of exciting television programmes on the reception of subsequent commercials. Unpublished working paper. Dept. Marketing, University of Kansas.

Soldow, G, F., \& Principe, V. 1981. Response to commercials as a function of programme context. Journal of Advertising Research, 21, 59-65. 
Television Audience Assessment, Inc. 1984. Programme impact and programme appeal: Qualitative ratings and commercial effectiveness. Unpublished paper. Boston.

Thorson E., Reeves, B., \& Schleuder, J. 1985. Message complexity and attention to television. Communication Research, 12, 427-454.

Thorson, E., \& Reeves, B. 1986. Effects of over-time measures of viewer liking and activity during programmes and commercials on memory for commercials. In R. Lutz (Ed.), Advances in consumer research, Vol. 13. Provo, UT: Association for Consumer Research.

Trompenaars, F. 1993. Riding the waves of culture. London: Nicholas Brealey.

Whipple, T., \& Courtney, A. 1981. How men and women judge humor: Advertising guidelines and research. In J. Leigh \& C. Martin (Ed.), Current issues and research in advertising (pp.43-56). Ann Arbor. MI: University of Michigan Graduate School of Business Administration.

(Manuscript received April 22, 2002; Revision accepted October 1, 2002) 